
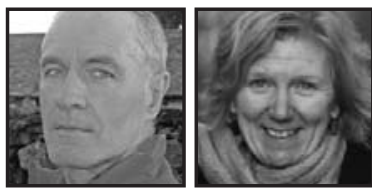

\title{
Image-Based Educational Research: Childlike Perspectives
}

\author{
Jon Prosser \& Catherine Burke
}

Note. From Chapter 34, "Image-Based Educational Research: Childlike Perspectives," by Jon Prosser and Catherine Burke, 2008, Handbook of the Arts in Qualitative Research: Perspectives, Methodologies, Examples and Issues (J. Gary Knowles and Ardra L. Cole, Eds.), Sage, 407-419. Rights holder: Sage Publications Inc Books. Reprinted with permission.

\section{ABSTRACT}

A new approach to researching childhood experience has become established whereby researchers are seeking out ways of giving voice to children and young people by "close listening" and engaging them in the research process. In this way, researchers can choose to adopt a childlike perspective, to recognize and pay due attention to children's multiple ways of "seeing" childhood in particular and the world in general.Visual research is well placed to access, interpret, and give voice to children's worlds. This is achieved by adopting child-sensitive research methods and by recognizing that children's experience and agency are important and worthy of study.

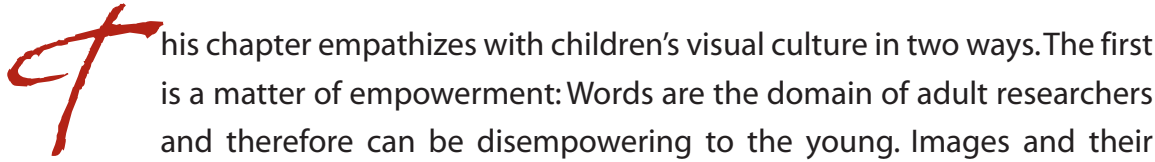
mode of production, on the other hand, are central to children's culture from a very early age and are therefore empowering. Put simply, children often feel more confident in creating drawings, photographs, and videos than words. Second, children's visual culture is central to any study of childhood. Children's everyday creative enthusiasms and aesthetic capacity for visualizing, space sharing, mobile technology, doodling, graffiti, sketching, dreaming, blogging, video, and photography are all expressions and representations of childhood. They are pivotal to understanding children's meaning making in their taken-for-granted lives. Striving to engage in children's lives by combining participatory research with children's visual culture is a worthy endeavor. 


\section{Methodological Background}

Observation of children has always played a pivotal role in researchers' endeavors to understand their physical, cognitive, and social worlds. Sociologists at the turn of the $20^{\text {th }}$ century used photographs to record and document observations of children's working and living conditions (e.g., Hine 1932; Riis, 1971). This body of work can now be viewed as lacking academic rigor and integrity. It was regarded by some as merely using images for political ends and therefore "muck-raking" (Stasz, 1979 , p. 134). However, the status of image-based research across the disciplines was significantly enhanced following the publication of Bateson and Mead's (1942) anthropological study Balinese Character. They made more than 25,000 photographs of Balinese culture, some of which critically documented children's lives, and organized them under emergent categories, such as "parents and children," "siblings," "stages of children's development" and "rites of passage." The next significant phase of development followed the publication of Collier's classic 1967 methodological text Visual Anthropology: Photography as a Research Method (updated and revised 1986) and Wagner's sociologically orientated Images of Information (1979). Currently, a gamut of texts, for example, Prosser (1998), Banks (2001), Rose (2001), Van Leeuwen and Jewitt (2001), and Pink (2004) provide insightful, varied, and rigorous discussion of contemporary visual methods, which can legitimately be applied to working with children. Child-focused researchers have adopted, adapted, and further developed these approaches for their own needs in child-centric visual studies, such as Seeing Kid's Worlds (Wagner, 1999), Seeing Beyond Violence: Children as Researchers (Egg, Schratz-Hadwich, Trubwasser, \& Walker, 2004), and The School I'd Like (Burke \& Grosvenor, 2003).

In the past, adults and children were seen as passive objects of research. Researchers' thinking has changed to encompass the general view that the subject of study has "the right as well as the ability to enter into discourse about the construction of their lives" (Banks, 2001, p. 9). Coupled with these philosophical changes are shifts in theory within the discipline of sociology of childhood. The long-held position that children should be viewed as being in a stage of transition to adulthood and therefore lacking worthwhile cognitive skills is no longer tenable. The current view is that children are active participants in their own social worlds and, given the means, are able to articulate and construct their own unique perspectives. This democratic and empowering model, which is personified as research "on, for and with" (Cameron, Frazer, Harvey, Rampton, \& Richardson, 1992, p. 22), recognizes children as dynamic members of the community with their own agendas. Hence, methodological 
advances in themselves are insufficient to understand children's increasingly complex lives. There is a requirement that researchers embrace an "on, for, and with children" mentality.

For social scientists an image-based approach is a pivotal element in understanding children's visual culture-its production, consumption, and meaning.Visual researchers have evolved methods and techniques that are collaborative, participatory, and insightful. Particular advances have been made, even involving very young children, in design-based visualization and planning. In sum, image-based research methods offer a powerful tool for realizing children's ways of seeing the designed present and imagining the designed future, capturing the visual culture of schools and other formal or informal edu-care environments in which children are placed, communicating to a wider audience the creative capacities of children in informing from their own experience, and shifting dominant paradigms of practice from research with children toward research by and for children.

\section{Visual Methods}

Accessing children's visual culture inevitably means understanding their perspectives. Children develop visual skills early in life, and visual methods draw on this strength. Children from as young as 2 years of age can explore feelings about their worlds, assisted by an adult photo-ethnographer. Older children can make their own photo-essays designed to explore and communicate their own experiences of, for example, the built school environment. Photo-collage techniques can be conducive to evaluative participation among those for whom lack of language or literacy is an impediment to communication. Children's views can be sought via diaries, drawings, modeling, and still and video camera work. The Internet can allow children to communicate visually about their lives from all continents, creating new visualizations and challenging assumptions by means of the photo-voice. All these possibilities have been achieved in practice by projects designed to recognize the implications of new ways of seeing children and childhood as a consequence of legal, theoretical, and social changes in the decades following the United Nations Convention on the Rights of the Child in 1990. 


\section{Photo-Elicitation With Children}

A common data gathering technique is photo-elicitation. Here photographs (or film, video, drawings, or objects) are introduced as part of an interview. The aim is to explore the significance or meaning of the images or objects with the respondent. The images can be created by the researcher specifically for the purposes of photoelicitation; they can be drawn from archives, magazines, or newspapers; or they can belong to the interviewee. Photo-elicitation has been used by visual anthropologists since the 1950s and is extensively used by a wide range of contemporary visual researchers (see Harper, 2002, for examples). However, it has no agreed protocol, and few studies have been undertaken to establish its validity as a research method. Nonetheless, the feeling is that "if it works, use it," and it is a technique that if used appropriately with children is capable of producing insightful data.

Researchers choose to use images or objects during initial discussions with young people because they are useful "icebreakers" and help to break down the power differential. Of course building bridges is important since potentially it leads to cooperation and engagement, but using visuals merely as a quick "way in" is to underplay the potential of the technique. Stand in a playground and point to objects or places, and bold children, generous with their time and knowledge, enthusiastically shower you with their insights_-pleased you are taking an interest in what they do. Moreover, they are visually astute and enjoy talking about images they or others have constructed, and photo-elicitation builds on this enthusiasm.

Photo-elicitation protocol in its simplest and most common form entails inserting a photograph into a research interview with the aim of drawing out the viewer's response. Interviewing children is a key method for data gathering, and interviewing with images or objects aids this approach in a number of ways. Banks (2001), for example, points to photographs acting as a neutral third party facilitating a more relaxed atmosphere for interviewing since eye-to-eye contact need not be maintained. This role for imagery is particularly worthwhile where children are interviewees and adults the interviewers since there are inescapable differences in status and power. The potential tension generated by face-to-face contact is lessened by mutual gazing at a photograph or the act of exploring an object together.

Children's willingness to pass comment on images depends on the image's content, their relationship to the content, and the context of viewing. It makes sense to young people and they feel more comfortable in sharing their insights if they are 
depicted since the image acts as an aide-mémoire, and they can more readily appreciate the researcher's need to gain their insights since they are visibly central actors. The timing, territory, membership, and nature of a photo-interview session are also important if children are to feel sufficiently confident and comfortable to pass on their ideas and beliefs.

Accessing a child's perceptions through image-elicitation may work by taking an indirect route. For example, rather than exploring a child's feelings about family relationships by looking through their family album, there is potential in using comics, magazines, or paintings depicting family relationships as a starting point, thereby allowing the child to dictate the pace and direction the interview takes. Children may feel less pressured if they don't speak directly to a researcher about a sensitive topic and may prefer working through a toy or doll. This approach, commonly used to build rapport or for diagnostic reasons, is a "projective technique" and requires careful, sometimes specialist handling (see Wakefield \& Underwager, 1998).

Video-elicitation was not popular in the past because it required cumbersome and nonportable equipment. Photo-elicitation was more popular since photographs are easily picked up, dropped, and rearranged in another sequence. However, portable DVD players are now the norm and widely accepted as part of a visual researcher's toolkit. This makes viewing of moving imagery more practical for empirical work, and one would expect to see an increase in the use of video-elicitation. There are many different but valid ways of conducting visual-elicitation. Whatever approach is taken, the media and topic should be part of children's everyday culture.

\section{Giving Children Still Cameras}

During the late 1960s experimental participatory visual studies were carried out by Worth and Adair (1972). They provided inner city teenagers, students, and representatives of the Navajo with movie cameras and film in an attempt to circumnavigate the problems caused by "outsiders" determining the form, content, and cultural context of filmmaking. In short, Worth and Adair attempted to shift away from the orthodox researcher-researched relationship by getting participants to act as the critical agents of data collection and interpretation. This approach was taken up by still photographers in the 1980s who emphasized the empowerment aspect of giving cameras to children. Jim Hubbard, ${ }^{1}$ a professional photographer, gave cameras to homeless children, children at risk, and American Indian children through a project 
called "Shooting Back." Ewald (2001), a photographer/educator² working around the same time, gave children cameras to aid self-expression and language development. In the 1990s numerous studies adapted Worth and Adair's (1972) approach and provided children and young adults with movie cameras or a combination of movie and still cameras (see Rollins, 1995).

Giving cameras to children and inviting them to photograph aspects of their lives gives children the freedom to create their own agenda in two ways: If the images are used later for photo-elicitation, it is their priorities that are the focus, and as narrative and a vehicle for personal expression (as, for example, in Caroline Wang's, n.d., work). The research community generally underestimates children's media abilities. Children of the $21^{\text {st }}$ century are familiar and adept with the technology of image production to such an extent that they are capable of being significant image makers themselves.

Sharples, Davison, Thomas, and Rudman (2003), in their systematic study of children as photographers, aged 7, 11, and 15 from five European countries, provide an insight into children's photographic interests and capacities. The study found that children across the age groups showed an increasing ability to distinguish the properties of images from the world they represent. This suggests that children should not necessarily be viewed as apprentice adult photographers since they exhibit their own distinctive intentions and products. Since children display critical capacities through their photography and are able to access physical and mental territory not available to adults, there is a case for perceiving them as fellow researchers. Given a particular focus and scenario, children will, driven by their innate imagination, create a "picture-led" narrative of their world (see, for example, Burke, 2005). At the center of giving children cameras is the idea of passing control to them-what Dell Clark (1999) calls "auto-driving."

There is a danger that the process of instructing children in what is required of them will perpetuate the unequal power relationship. Researchers will always have to make judgments about the need to "guide" students and take account of the intentionality of researchers and informants. A common strategy, based on the assumption that children and young people are experts in their own lives, is to invite them to photograph their own special or everyday environments. The Mosaic Approach (Clark \& Moss, 2001) adopts standard research methods like observation but in addition suggests providing 2-to 4-year-old children with single-use cameras to photograph what was important to them in their nursery setting. The researcher is taken on a "tour" of the setting by children who also provide a running commentary on their regular 
activities. The children were responsible for deciding what and how to record, either by photograph, drawings, or tape recorder. Clark and Moss (2001) make an important point arguing that cameras offer young children the opportunity to produce a finished product in which they can take pride and that they know is valued. Children who have seen the members of their family take photographs, pored over family albums, or looked at photographs in books and comics know that photographs have a value in the "adult world." This is not always the case with children's own drawings and paintings.

Another approach is to ask older children to work collaboratively (child-tochild) to record the lives of younger children. So, for example, a 4-year-old would be asked to use a camera to record the everyday events of an 8-month-old in "the baby room." The photographs produced by the children are later used as discussion points with the older children, the staff in the setting, and the younger children's parents. As this approach shows, age is rarely a barrier to giving young people single-use cameras in research settings, although underestimating their capacities is.

\section{Giving Children Digital Video Cameras}

Word-based research tends to reproduce hierarchies exacerbating differences between researchers and the researched. Image-making technologies have the potential to reduce the distance between researchers and children, producing a more democratic model. Providing children with digital video cameras, often called "participative video," offers transformative potential when the practice of "looking at" becomes "looking alongside." Nonetheless, sensitive and reflexive negotiation of research relationships is critical if hierarchical power relations are not to be reproduced through researcher-dominated procedures leading to subjugated children's imagery. The balance between the responsibilities, needs, and intentions of researchers and informants is difficult to achieve but needs to be transparent to all parties. Where video technology remains physically and metaphorically in the hands of the researchers and is used to capture, document, or note-take a scene, it remains an extension of adult gaze and should be understood as such.

A central aim of the participatory video process is to create a video narrative that conveys what children want to communicate in the manner they wish to communicate. Of course pragmatic decisions about what should be framed and how the sequences are to be organized to tell a story bring into question the negotiation 
roles. Critical reflection on two elements is fundamental to producing trustworthy outcomes. First, participatory video demands attention to the exercise of power within sets of dynamic research relationships reflected in both researcher-children and children-children groupings. Second, children are looking and sense-making before they can walk or talk and quickly adapt to contemporary pervasive visual culture, and adults should accept that children have substantial filmmaking potential.

Young people are often familiar with the technology of image production and capable of becoming image makers themselves following basic instruction. They may mimic adult filming methods even to the extent of adopting a preplanned storyboard approach. However, they are merely embracing generic visual culture, and this should not be a signal for heavy-handed researcher involvement with the express aim of creating an adult notion of a "good," that is, technically proficient film reflecting adult intellectual concerns. Where practicable, children's own unique filmic visual subculture should prevail over researchers' conventions, which are traditionally aligned with documentary film or scientific observation.

A wide range of children-centered topics and research questions are predisposed to the participatory video process. It may be that young people's social class, culture, and situation influence what they want to film (Rich \& Chalfen, 1999). Nonetheless, focusing on their everyday lived experience takes advantage of the time-based properties of film. Quite specific contexts are useful as a starting point. Children's homes or social lives, for example, provide situations where they are confident in their own knowledge and that act as a "springboard" for filming. Moreover, key insights could be gained when children and young people film the changing nexus of activities and spheres of influence as they undergo significant transitions in their lives, for example, an illness they are experiencing, leaving school and going to work, or as a means of creating a record of their own physical and emotional space.

\section{Concept Mapping}

One important approach to identifying and visually representing children's perspectives on a range of complex topics is through concept mapping. This is defined by Novak and Gowin (1984) as "a visual road map showing some of the pathways we may take to connect meanings of concepts in propositions" (p. 15). It is most commonly used for tracking the development of children's learning, as a diagnostic tool for evaluating their progress, and as an aide to help children learn how to learn 
(Georghiades, 2000). These approaches are premised on a constructivist notion of learning and on the idea that learners frame their understanding of new knowledge on preexisting beliefs. However, importantly, concept mapping can be used as a tool to articulate children's perceptions, promote reflection, and generate and communicate complex ideas on a range of topics. An example of a child-created concept map in which the starting point is "food" and the subconcepts need to be related to one another is given in Figure 1.

A search of the Internet for "concept mapping" will uncover a plethora of commercially available word-graphic tools. A simple version of a concept map, sometimes referred to as a "mind map," consists of a central word or concept around which about 5 to 10 main ideas are drawn, and then an additional 5 to 10 ideas are drawn that relate to each of those main ideas (Buzan, 1995). Whereas mind maps have only one main concept represented like a (family) tree, concept mapping may require a network of representation. Concept maps may take various forms. Novak and Gowin (1984) propose a hierarchical form in which key concepts are placed at the top and lesser concepts positioned lower down on a page. Others prefer a "spider" map in which the trigger word or pivotal concept is placed centrally (see Figure 1) and participants are asked to provide additional linked concepts.

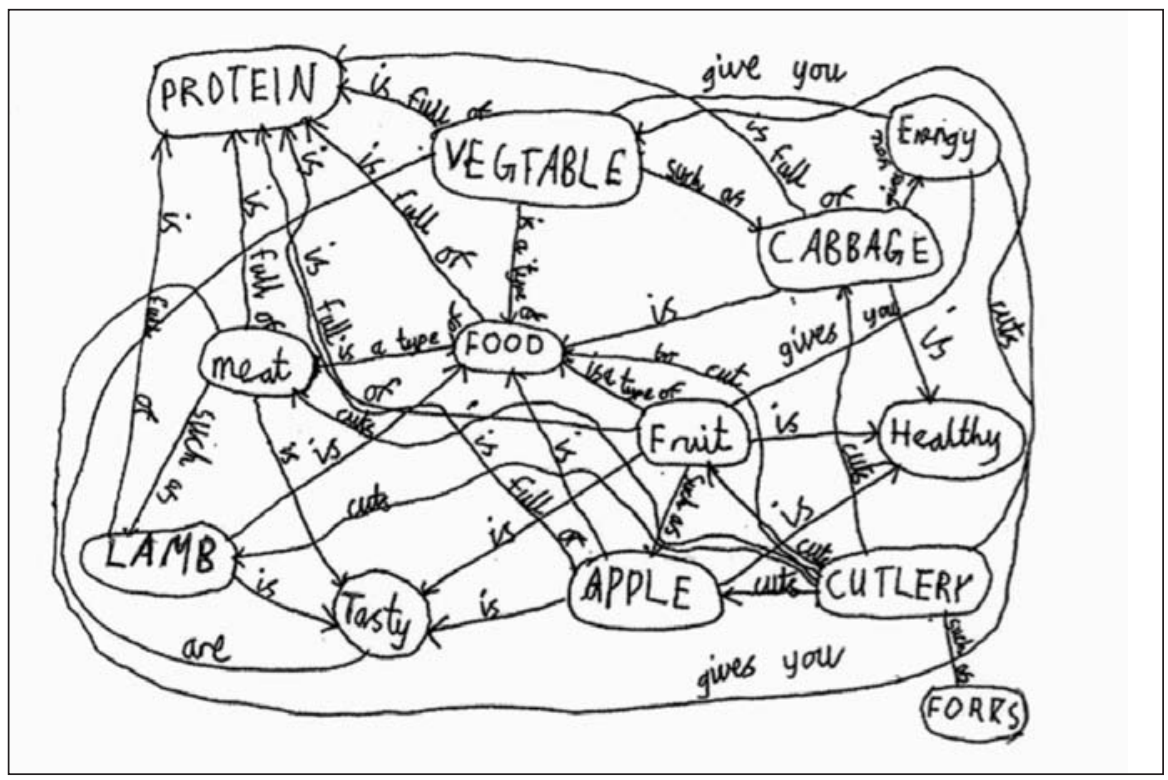

Fig. 1: An example of a concept map from Georghiades and Parla-Petrou (2001)

SOURCE: From Georghiacles, P., \& Parla-Petrou, E. (2001). Diverse use of concept mapping across two domains: The cases of primary food and science education. Presented at the British Educational Research Association Annual Conferences, University of Leeds, 13-15, September. Used with permission of Petros Georghiades. 
Since children will be unfamiliar with concept mapping; important terms like concept, mapping, and linking words will need explanation, discussion, and activities. A useful approach may be to involve a group of children in a joint construction of a concept map and to provide examples of concept maps of unrelated themes.

\section{Draw and Write}

Many of the above methods use visuals as a stimulus for communication. Images that have meaning for children may be used within orthodox research methods such as questionnaires to identify and differentiate between levels of response. Figure 2, for example, illustrates how Snoopy, a widely known cartoon character, is depicted in various poses and children are asked to circle the pose that corresponds to their feelings. However, the "draw and write" approach is based on the notion that "starting where the children are," that is, children's own drawings and words, is of fundamental significance.

Children have the ability to capture feelings and emotions through drawings and paintings while lacking an equally expressive written or spoken language. This opens up a range of active participation in research to disadvantaged children. Special educational needs (SEN) children have been habitually and systematically excluded from discussions about their education. The underlying assumption has been that they are neither well informed nor sufficiently articulate to contribute. To be a child and disabled is to be doubly disadvantaged in terms of voice.

\section{How do you feel when your teacher reads a story aloud?}
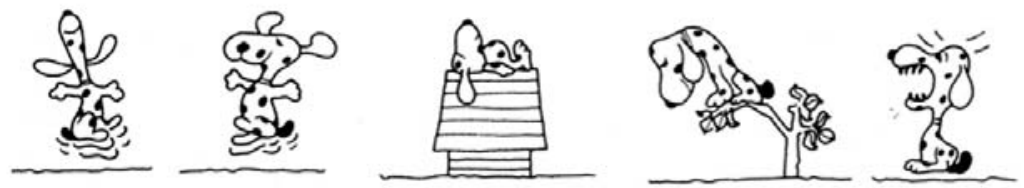

2. How do you feel when someone gives you a book for a present?
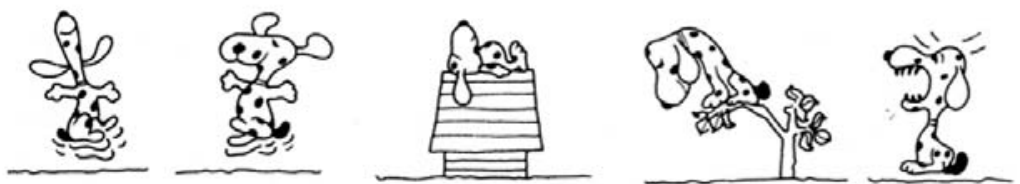

Fig. 2: Snoopy questionnaire

SOURCE: From Hopkins, D, (1985), A Teacher's Guide to Classroom Research 3/e, published by Open University Press, Milton Keynes, UK, Reproduced with the kind permission of the Open University Press Publishing Company. 
There are many visual methods and techniques that help SEN children to learn and that can be used to understand their experiences of the world. The "draw and write" method was used to help Jane, a young girl with a fire phobia who was experiencing recurrent nightmares with a fire theme. She was autistic and aphasic with learning difficulties, experienced problems relating to others, and was unable to speak or write expressively. Jane was asked to draw her nightmare (Figure 3), and a more able peer, her only friend, helped her to write a prayer to accompany the image. It became apparent from the drawing and words and later interviews that Jane had seen TV footage of the New York 9/11 disaster. She was deeply disturbed by the experience, particularly by the sight of people leaping from the World Trade Center building to avoid the fire. Later, counseling based on the visual data enabled Jane to escape the nightly replay of the film loop in her mind that caused the nightmares to recur.

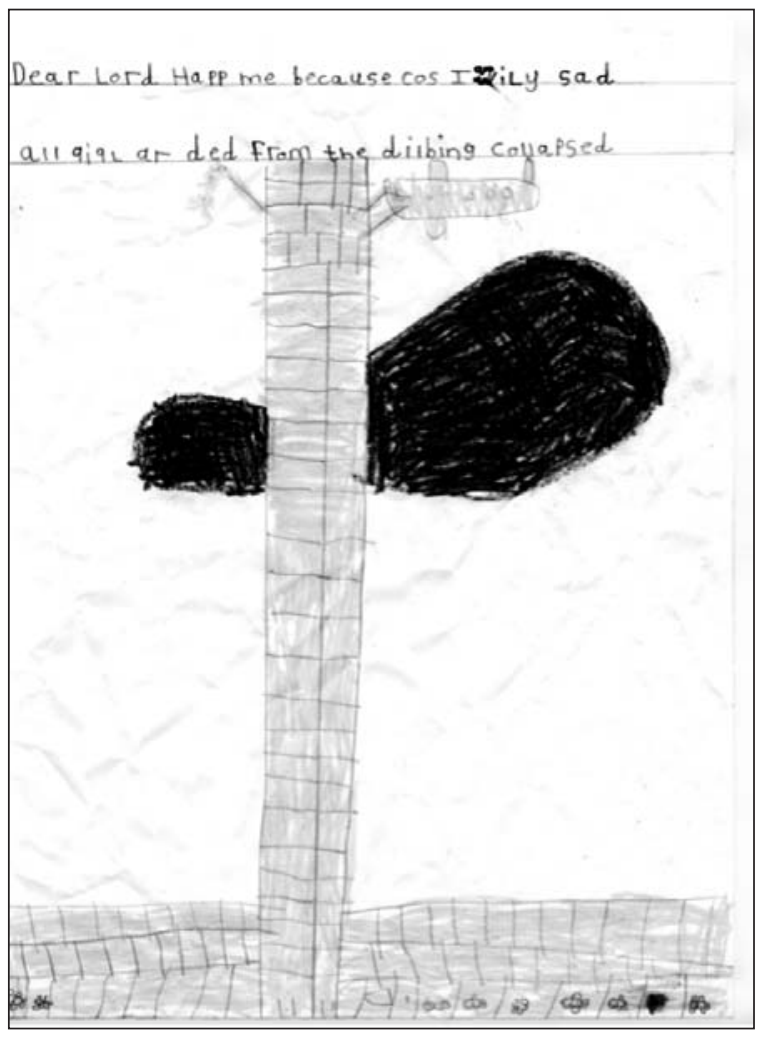

Fig. 3: Drawing and words by Jane (name changed) with help from a friend 
Interpreting children's drawings is particularly difficult but rewarding. DiemWille (2001), adopting a psychoanalytical perspective, argues that drawings show a child's emotional state better than verbal descriptions since they are "expressions of the unconscious emotional aspects of a person" (p. 119). Adopting the view that children's drawings are expressions of their "inner world," Figure 3 gains significance suggesting that in addition to distinguishing likes and dislikes, it represents Jane in terms of an emotional map.

\section{Visual Research as a Vehicle for Change}

Cameras can be employed in imaginative ways to enable children and young people to confront difficult aspects of their lives. "Seeing Beyond Violence: Children as Researchers" (Egg, Schratz-Hadwich, Trubwasser, \& Walker, 2004) is a research project that foregrounds children and young people's photography. Children's understanding of violence in Colombia, Thailand, India, and Nicaragua was explored through a methodological device that required that they use digital cameras to photograph the opposite of violence. Adult researchers were in the background and acted as "assistants" to the children. This repositioning of the adult in the research field is an important shift if children are to wear the mantle of researcher. $A$ combination of "digital ethnography" with symbolic interactionism was intended to give children more than a voice but also provide the opportunity to build visual evidence of their social reality. Here the images are the priority; they are not merely present as a tool to elicit language or to illustrate a report.

Cameras are now becoming used quite commonly as part of a method to allow the very youngest children to express their views. Sometimes the adult researcher will take the photograph for the child from the child's own height; sometimes they will leave the camera with professionals to allow them to record activities. Polaroid cameras were used with the youngest children in a study on children's views on child-care quality, allowing instant conversations about the photographs to be recorded. The children took the researcher on a tour of their childcare setting and then took photographs of what they liked or disliked (Clark \& Moss, 2001). The reports of such research rarely if ever present the photographs created by children or include these nontextual views of children in their summaries and conclusions. They appear to be tools to create engagement and participation while the language-what the child says-is all important. 
International nongovernmental organizations such as UNICEF are employing visual means of empowering children. Drawing allows the youngest children to "speak." At the United Nations' Special Session on Children (May 8-10, 2002; http://www.unicef.orglspecialsession), the voices of nearly 34,000 children from more than 125 countries were heard through their paintings. In another project, more than 500 children and young people from 45 countries captured images of their lives on camera as part of "Imagine:Your Photos Will Open My Eyes," a joint youth photography project of the German Agency for Technical Cooperation (GTZ) and Philip Abresch, a journalist in Berlin. Such projects illustrate and realize the potential available through information and communication technology (ICT) as digital photo exhibitions and image-based online conversations can enable cross-cultural collaboration between and among young people. Save the Children's "Eye to Eye" project does just this. The project enables Palestinian children living in refugee camps in Lebanon to record their lives using cameras and video. The result is a vivid and accessible online resource for communities of children and their teachers throughout the world (http://www.savethechildren.org.uk/eyetoeye). Photovoice (Wang, n.d.) is an organization committed to the principle of enabling those traditionally not the subject of photography to be its creator and thus works with street children throughout the world, allowing them control over ways of seeing them. They have worked in Vietnam, Afghanistan, the Congo, Nepal, and the United Kingdom. A key intention of this initiative is to enable participants to become advocates for change.

\section{The Dilemmas of Visual Ethics}

Research with children is fraught with complex ethical issues. A visual dimension adds to the list of potential dilemmas and deserves more space than encapsulated within this brief review. The most common principles that underpin ethical codes of practice have been referred to as "mutual respect, non-coercion and non-manipulation, and support for democratic values and institutions" (House, 1993, p. 167). This is a useful starting point, but visual ethical principles are best discussed in concrete situations (Pink, 2004; Prosser, 2000; Simons \& Usher, 2000).

Participatory research by its nature is ethical-potentially. Just as action research shifts power to practitioners, an ethical participative epistemology empowers the disempowered and suggests a shift in the power balance away from researchers toward respondents. The notion that research is solely concerned with finding out about the world and is essentially politically neutral is rejected by emancipatory 
research. An aim of emancipatory and participatory research is to reduce discrimination, marginalization, and inequality and increase empowerment through social action, that is, the participation of children within a child-centered methodology.

Informed consent is central to good ethical practice. With all forms of longitudinal ethnographic and emergent studies with children, the notion of informed consent is problematic since direction and outcomes are variable. The notion of "provisional consent" may be appropriate in these circumstances. Here, the ongoing relationship between researcher and children is seen as evolving and dependent on reciprocal trust and collaboration. This enables ethical problems to be explored and resolved as they emerge within specific contexts and provides the possibility for children (and parents) to opt in or out at different phases.

Anonymity, unless participants choose to be identified and are fully aware of potential repercussions, is common practice in social science research. It is possible to blur or "cloak" children's faces in photographs using a relatively simple pixel reduction technique, thereby blurring their faces and protecting their identity. Where data are intended for reproduction and wider consumption, it is possible to restrict access to video data on CDs and Web sites using encryption. However, using visual images of young people or created by them makes issues of anonymity problematic. In America, for example, where restrictive research codes of practice operate, authors of artwork or those depicted in the artwork of others may be assured of anonymity, but in doing so they are denied the choice to be named and their work celebrated. This is questionable ethical practice.

There are times when children are happy for their work to be displayed publicly (and the researcher is keen to publicize their achievements) but wish to remain anonymous (for example the author of Figure 3). Equally, there are occasions when a researcher decides, against the author's wishes, not to name the creator because in the researcher's judgment, the author may be damaged or put in danger. These dilemmas are only the tip of the ethical "iceberg" and not easily resolved. Adult visual researchers with child visual researchers will need to make decisions and resolve ethical problems as they arise. This is not an avocation of ad hoc decision making since knowledge, planning, and awareness of potential problems prior to conducting visual research are central to ethical practice. 


\section{Conclusions}

In this chapter, we explored the possibilities of image-based research with children. Childlike perspectives, we hope we have demonstrated, are worthwhile pursuing, necessary to include in ethical practice, and complex to attain. Images, art, and interpretation of the visual in the research approach can facilitate childlike perspectives and empower the child participant as researcher or as subject in research. Seeing the world through the eyes of a child means literally getting down to the eye level and realizing the difference that scale makes in a person's view of the world. Image-based research approaches, principles, and practices, illustrated in this chapter, can bring the adult closer to the view of the child in the research process. An ethical practice will not only realize the usual agreed conventions on consent and protection of rights but also be sensitive to the particular status and position of the child in its social and cultural context.

\section{Notes}

1. Jim Hubbard's work can be found at http://www.shootingback.org. He teaches photography to street youth and conducts workshops around the world through universities and government agencies.

2. Ewald works through Duke's Center for Documentary Studies, Durham, NC. Her Web site is http://globetrotter.berkley.edu/Ewald/

\section{References}

Banks, M. (2001). Visual methods in social research. London: Sage.

Bateson, G., \& Mead, M. (1942). Balinese character: A photographic analysis. New York: New York Academy of Sciences.

Burke, C. (2005). "Play in focus": Children researching their own spaces and places for play. Children, Youth, and Environments, 15(1), 23-53.
Burke, C., \& Grosvenor, 1. (2003). The school I'd like. London: RoutledgeFalmer.

Buzan, T. (1995). The mind map book. London: BBC Books.

Cameron, D., Frazer, E., Harvey, P., Rampton, M. B. H., \& Richardson, K. (1992). Researching language. London: Routledge. 
Clark, A., \& Moss, P. (2001). Listening to young children: The mosaic approach. London: The National Children's Bureau \& Joseph Rowntree Foundation.

Collier, J. (1986). Visual anthropology: Photography as a research method (Rev ed.). Albuquerque: University of New Mexico Press. (Original work published 1967)

Dell Clark, C. (1999). The autodriven interview: A photographic viewfinder into children's experience. Visual Sociology, 14, 39-50.

Diem-Wille, G. (2001). A therapeutic perspective: The use of drawings in child psycho-analysis and social science. In T. Van Leeuwen \& C. Jewitt (Eds.), Handbook of visual communication (pp. 119-133). London: Sage.

Egg, P., Schratz-Hadwich, B., Trubwasser, G., \& Walker, R. (2004). Seeing beyond violence: Children as researchers. Innsbruck, Austria: Herman Gmeiner Academy.

Ewald, W. (2001). I wanna take me a picture: Teaching writing and photography to children. Boston: Lynhurst Books and Beacon Press.

Georghiades, P. (2000). Beyond conceptual change learning in science education: Focusing on transfer, durability, and metacognition. Educational Research, 42(2), 119-139.

Harper, D. (2002). Talking about pictures: A case for photo-elicitation. Visual Studies, 17(1), 13-26.

Hine, L (1932). Men at work. New York: Macmillan.

House, E. R. (1993). Professional evaluation: Social impact and political consequences. London: Sage.

Novak, J. D., \& Gowin, D. R. (1984). Learning how to learn. New York: Cambridge University Press.

Pink, S. (2004). Doing visual ethnography. London: Sage.

Prosser, J. (Ed.). (1998). Image-based research: A sourcebook for qualitative researchers. London: Falmer Press.
Prosser, J. (2000). The moral maze of visual ethics. In H. Simons \& R. Usher (Eds.), Situated ethics in educational research (pp. 116-132). London: Routledge Falmer.

Rich, M., \& Chalfen, R. (1999). Showing and telling: Children teaching physicians with visual narrative. Visual Sociology. 14, 51-71.

Riis, J. A. (1971). How the other half lives. New York: Dover.

Rollins, T. (1995). Kids of survival. In N. Paley (Ed.). Finding art's place (pp. 92-98). London: Routledge.

Rose, G. (2001). Visual methodologies: An introduction to the interpretation of visual materials. London: Sage.

Sharples, M., Davison, L., Thomas, G., \& Rudman, P. D. (2003). Children as photographers: An analysis of children's graphic behaviour and intentions at three age levels. Visual Communication, 2(3), 303-330.

Simons, H., \& Usher, R. (2000). Situated ethics in educational research. London: Routledge Falmer.

Stasz, C. (1979). The early history of visual sociology. In J. Wagner (Ed.), Images of information: Still photography in the social sciences. Beverly Hills, CA: Sage.

Van Leeuwen, T., \& Jewitt, C. (Eds.). (2001). Handbook of visual analysis. London: Sage.

Wagner, J. (Ed.). (1979). Images of information: Still photography in the social sciences. Beverly Hills, CA: Sage.

Wagner, J. (Ed.). (1999). Seeing kid's worlds [Special issue]. Visual Sociology, 14.

Wakefield, H., \& Underwager, R. (1998). The application of images in child abuse investigations. In J. Prosser (Ed.), Image-based research: A sourcebook for qualitative researchers (pp. 176-194). London: Falmer Press.

Wang, C. (n.d.). Photovoice. Retrieved May 24, 2007, from http://www.photovoice.com/ index.html

Worth, S., \& Adair, J. (1972). Through Navajo eyes: Explorations in film communication and anthropology. Bloomington: Indiana University Press. 


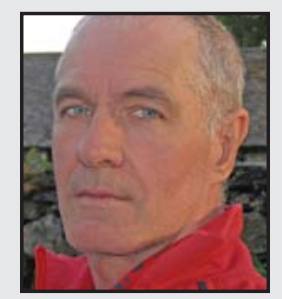

Jon Prosser works in International Education Management at Leeds University, United Kingdom. He is perhaps best known for editing Image-based Research: A Sourcebook for Qualitative Researchers, (1998) which was the first book in the field to present visual research as a theoretically and methodologically varied approach to conducting research. Currently he is contributing to the groundbreaking Realities program based at the Morgan Centre, University of Manchester. He is also involved in HIV/AIDS research in South Africa, creating a Special Needs School in Mongolia, and creating calendars for Riding for the Disabled Association.

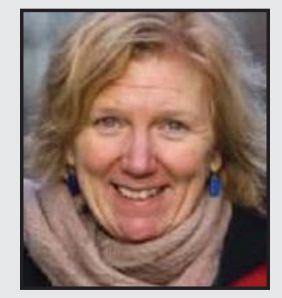

Catherine Burke, $\mathrm{PhD}$, is Senior Lecturer in History of Education at the Faculty of Education, University of Cambridge, UK. She is a historian currently engaged with cultural and material histories of educational contexts and of childhood in the 19th, 20th and $21^{\text {st }}$ centuries. She has researched and published widely on the history of educational spaces, the participation of children in the design of school, and the use of visual sources in educational research. She is currently the editor of the Sources and Interpretations section of History of Education Journal. 